\title{
A study on cardiac autonomic modulation during pregnancy by non-invasive heart rate variability measurement
}

Pritesh Hariprasad Gandhi, Hemant B. Mehta, Ashish V. Gokhale', Chetan B. Desai, Pradnya A. Gokhale, Chinmay J. Shah

Departments of Physiology and ${ }^{1}$ Obstetrics and Gynaecology, Government Medical College, Sir T Hospital, Bhavnagar, Gujarat, India

Address for the Correspondence: Dr. Pritesh Hariprasad Gandhi, Plot No-9, Ramabaug Society, Government Medical College, Anantwadi, Bhavnagar, Gujarat - 364 001, India.

E-mail: priteshgandhi2@gmail.com

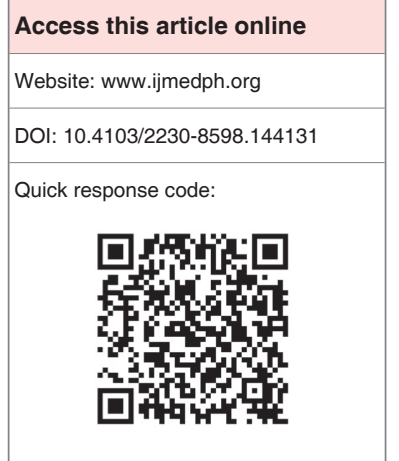

Purpose: Remarkable and uncontrollable changes with modification during pregnancy are connected with the autonomic control and consequently with the heart rate variability (HRV). Heart rate variability is a sum of different mechanisms and if pregnancy is a state of change, these modifications could be extracted from HRV analysis. Objective: To assess the effect of pregnancy on heart rate variability among pregnant mothers during first trimester of pregnancy and third trimester of pregnancy. Materials and Methods: HRV was measured for 5 minutes of continuous recording of electrocardiogram (ECG) lead II, using windows based HRV analysis system variowin-HR after obtaining permission from the Institutional Review Board of Government Medical College, Bhavnagar and written consent from 30 pregnant subjects and 30 non-pregnant control subjects at autonomic function lab, Dept of Physiology, Bhavnagar. Result: Frequency domain parameters, very low frequency (VLF), low frequency (LF), high frequency (HF) and HF normalized unit (nu) were significantly decreased and LF (nu) and LF/HF significantly increased in pregnant subject in $3^{\text {rd }}$ trimester as compared to their $1^{\text {st }}$ trimester of pregnancy. Time Domain parameters like SDNN, RMSSD, SDSD, NN50 count, pNN50, SD1/SD2, triangular HRV index and average R-R interval were significantly decreased during $3^{\text {rd }}$ trimester of pregnancy. Conclusion: The inhibition of resting parasympathetic activity or vagal blockage and an increment of the sympathetic modulation during the $3^{\text {rd }}$ third trimester of gestation in pregnancy as compared to their $1^{\text {st }}$ trimester and healthy non-pregnant subjects. Sympathovagal imbalance and abnormally low HRV may more pronounce during later stage of normal pregnancy.

Key words: Autonomic function test, gestation, heart rate variability, pregnancy

\section{INTRODUCTION}

The last three decades have witnessed the recognition of a significant relationship between the autonomic nervous system and cardiovascular mortality, including sudden cardiac death. ${ }^{[1]}$ Heart rate variability (HRV) is a non-invasive, easy and economical technique to assess the status of autonomic nervous regulation of cardio vascular system. Heart with a stable and regular heart beat periodically is now considered as the marker for a poor prognostic for longevity. ${ }^{[2]} \mathrm{HRV}$ studies enhance understanding of physiological phenomenon of heart activity especially during pregnancy. The changes in the function of every regulatory system during pregnancy are initiated by ovarian and placental hormones in the first trimester, but may also be modified by placental and fetal endocrine factors as gestational age advances. Pregnancy-induced effects on cardiovascular function are increases in heart rate (HR), stroke volume (SV), and cardiac output. ${ }^{[3,4]}$ These changes result from the interactive effects of a primary reduction in peripheral vascular resistance, ${ }^{[5]}$ cardiac autonomic modulation and baroreflex function that lead to a higher resting heart rate.

It is well established that high-frequency (HF) power $(0.15-0.40 \mathrm{~Hz})$ of $\mathrm{HRV}$ is mediated by parasympathetic nervous system (PNS) modulation and respiratory sinus arrhythmia, ${ }^{[6-8]}$ whereas low-frequency (LF) power $(0.03-0.15 \mathrm{~Hz})$ reflects both sympathetic nervous system (SNS) and parasympathetic nervous system (PNS) autonomic influences. ${ }^{[8,9]}$ The ratio of low-frequency power to high-frequency power (LF/HF) has been used to reflect cardiac sympathetic modulation (SNS 
indicator). ${ }^{[3,9]}$ Ekholm et al. studies on cardiac autonomic function in human pregnancy have produced conflicting results. Their findings of reduced total power ${ }^{[10,11]}$ and attenuated HR responses to orthostatic tests and the Valsalva maneuver ${ }^{[11]}$ suggest that cardiac parasympathetic modulation is reduced in the resting state during mid pregnancy (22-29 wk of gestation). Studies conducted in early to mid gestation $(11-27 \mathrm{wk})^{[12]}$ were reported reduction in low-frequency HRV during the day and reduction in high-frequency HRV at night.

\section{OBJECTIVE}

- To assess the heart rate variability during first trimester of gestation in pregnancy and third trimester of gestation in pregnancy.

- To study the effect of various stages of normal pregnancy on heart rate variability.

\section{MATERIALS AND METHODS}

Pregnant subjects were enrolled into the study from Obstetric department after permission was taken from Institutional Review Board (IRB) and Human Ethics Committee of Government Medical College, Bhavnagar. This study was carried out at autonomic nerve function lab, Dept. of Physiology, Govt. Medical College and Sir T Hospital, Bhavnagar. Short HRV was measured for 5 minutes from continuous recording of ECG (heart rate) using windows based HRV analysis system variowin-HR.

\section{Sample size}

Due to pregnancy termination or development of pregnancyinduced complication, out of 42 in $1^{\text {st }}$ visit, 30 pregnant subjects were selected for $2^{\text {nd }}$ visit. 30 normal pregnant subjects and 30 ages matched healthy non-pregnant control subjects were enrolled.

\section{Criteria for selection}

\section{Inclusion criteria of pregnant subjects}

Age of 18 yrs- $45 \mathrm{yrs}$ and $\mathrm{Hb}$ is of $>9.0 \mathrm{gm} \%$ pregnant subject and giving written consent for HRV recording.

\section{Exclusion criteria of pregnant subjects}

Any illness and pregnancy-induced complication develop at any stage of pregnancy during this study.

\section{Inclusion criteria of non-pregnant subjects}

Age of 18 yrs-45 yrs non-pregnant subject having $\mathrm{Hb}>9.0 \%$ and ready for giving written consent for HRV recording.

\section{Exclusion criteria of controls}

Any illness.

\section{Procedure}

In the presence of relatives and one female staff, all participants were allowed to relax for ten minutes. Case record form containing personal information of subjects, anthropological measurements, last menstrual period, total month of amenorrhea, obstetric history, clinical history and vitals were filled up. Subjects were asked to lie down in a supine position and remain quiet, without speaking or making any movements for 5 minutes.

Four electrodes were placed at both infraclavicular and both hypochondrial regions of the subjects. HRV were measured by continuous lead II ECG recording for 5 minutes (short-term HRV) based on R-R interval. The pregnant women were called for two times for HRV measurement, during $1^{\text {st }}$ trimester of gestation (6-12 weeks of pregnancy) and during $3^{\text {rd }}$ trimester of gestation (25-36 weeks of pregnancy). Both time domain (SDNN, RMSSD, SDSD, NN50 Count, pNN50\%) and frequency domain (VLF, LF, HF, LF/ HF ratio) parameters of HRV analyses were measured.

\section{Statistical analysis}

We were using graph Pad InStat statistical software for data analysis.

\section{RESULTS}

There is no any significant difference in age and height between cases and controls. This infers that the case subjects and healthy controls were ideally matched for age and height to relatively nullify the effect of confounding variable factor on HRV. The weight and body mass index (BMI) values were statistically significant in both groups. $\left\{1^{\text {st }}\right.$ trimester of gestation and Controls; $3^{\text {rd }}$ trimester of gestation and Controls $\}$ [Table 1a and b].

There were no significant difference in values of HRV parameters among $1^{\text {st }}$ trimester subject group and control group. This infers that in early normal pregnancy, there may not be any change in the cardiac autonomic regulatory mechanism in spite of hormonal changes. This may be due to other compensatory mechanism [Table 2].

There was significant decrease in both frequency domain parameters and time domain parameters during $3^{\text {rd }}$ trimester of gestation in pregnancy as compared to healthy control [Table 3].

\begin{tabular}{|c|c|c|c|}
\hline \multicolumn{4}{|c|}{$\begin{array}{l}\text { Table 1: (a) Mean } \pm \text { SD values of anthropological } \\
\text { measurement among } 1^{\text {st }} \text { trimester of gestation in } \\
\text { pregnant subject and } 3^{\text {rd }} \text { trimester of pregnancy } \\
\text { and healthy non pregnant control subjects }\end{array}$} \\
\hline Parameters & $\begin{array}{c}1^{\text {st }} \text { trimester of } \\
\text { gestation }(n=30)\end{array}$ & $\begin{array}{c}\text { Control non } \\
\text { pregnant }(n=30)\end{array}$ & $P$-value \\
\hline Age (yrs) & $24.63 \pm 3.05$ & $23.43 \pm 2.91$ & $0.1240, \mathrm{NS}$ \\
\hline $\mathrm{Ht}(\mathrm{cm})$ & $151.03 \pm 2.92$ & $151.63 \pm 4.39$ & $0.5355, \mathrm{NS}$ \\
\hline Wt (kg) & $48.5 \pm 5.81$ & $51.7 \pm 5.33$ & $0.030, \mathrm{~S}$ \\
\hline BMI & $21.24 \pm 2.28$ & $22.49 \pm 2.3$ & $0.0382, \mathrm{~S}$ \\
\hline Parameters & $\begin{array}{l}3^{\text {rd }} \text { trimester of } \\
\text { gestation }\end{array}$ & $\begin{array}{c}\text { Control non } \\
\text { pregnant }\end{array}$ & $P$-value \\
\hline Wt (kg) & $53.67 \pm 6.31$ & $51.7 \pm 5.33$ & $0.1969, \mathrm{NS}$ \\
\hline BMI & $23.5 \pm 2.43$ & $22.49 \pm 2.3$ & $0.1038, \mathrm{NS}$ \\
\hline
\end{tabular}

$\mathrm{SD}=$ Standard deviation, $n=$ Number of participants, NS = No significance, $\mathrm{S}=$ Significance, $P$-value $<0.05$ indicates significance 


\begin{tabular}{|c|c|c|c|}
\hline Parameters & $\begin{array}{c}1^{\text {st }} \text { trimester } \\
\text { of gestation in } \\
\text { pregnant subject }\end{array}$ & $\begin{array}{l}3^{\text {rd }} \text { trimester } \\
\text { of gestation in } \\
\text { pregnant subject }\end{array}$ & $P$-value \\
\hline Wt (kg) & $48.5 \pm 5.81$ & $53.67 \pm 6.31$ & $0.0016, \mathrm{~S}$ \\
\hline BMI & $21.24 \pm 2.28$ & $23.5 \pm 2.43$ & $0.0004, \mathrm{~S}$ \\
\hline Parity & $1.333 \pm 0.6814$ & $1.333 \pm 0.6814$ & $0.99, \mathrm{NS}$ \\
\hline $\mathrm{Hb} \%$ & $9.95 \pm 0.36$ & $9.82 \pm 0.43$ & $0.2091, \mathrm{NS}$ \\
\hline SBP & $115.87 \pm 8.37$ & $124.5 \pm 7.33$ & $0.0001, \mathrm{~S}$ \\
\hline DBP & $72.6 \pm 5.31$ & $77.53 \pm 5.03$ & $0.0005, \mathrm{~S}$ \\
\hline $\begin{array}{l}\text { No Weeks of } \\
\text { gestation }\end{array}$ & $9.27 \pm 1.72$ & $28.3 \pm 1.51$ & - \\
\hline
\end{tabular}

Frequency domain parameters like VLF, LF, HF and HF (nu) were significantly decreased and LF (nu) and LF/HF were significantly increased during $3^{\text {rd }}$ trimester of gestation as compared with their $1^{\text {st }}$ trimester of pregnancy. In time domain (power spectral) parameters, there are decreased mean values of SDNN, RMSSD, SDSD, NN50 count, pNN50, SD1/SD2. Triangular HRV index and average R-R interval are more decreased during $3^{\text {rd }}$ trimester of pregnancy. Heart Rate and Mode values are increased in $3^{\text {rd }}$ trimester as compare with $1^{\text {st }}$ trimester [Table 4].

\section{DISCUSSION}

As per Table 2, there were no statistical significant difference in the mean values of frequency domain parameters and time domain parameters among the $1^{\text {st }}$ trimester of gestation in pregnancy subjects

\begin{tabular}{|c|c|c|c|}
\hline Parameters & $\begin{array}{l}1^{\text {st }} \text { trimester of gestation in pregnant subject } \\
(\text { Mean } \pm \text { SD) }\end{array}$ & $\begin{array}{l}\text { Controls non pregnant } \\
\text { Mean } \pm \text { SD }\end{array}$ & $P$-value \\
\hline \multicolumn{4}{|c|}{ Frequency domain parameters } \\
\hline $\operatorname{VLF}\left(\mathrm{ms}^{2}\right)$ & $1107.7 \pm 720.42$ & $1059.9 \pm 503.57$ & $0.4926, \mathrm{NS}$ \\
\hline $\operatorname{LF}\left(\mathrm{ms}^{2}\right)$ & $\downarrow 899.19 \pm 527.80$ & $979.49 \pm 696.1$ & 0.6166, NS \\
\hline $\mathrm{HF}\left(\mathrm{ms}^{2}\right)$ & $\downarrow 801.06 \pm 898.32$ & $906.72 \pm 674.94$ & 0.6085, NS \\
\hline LF (nu) & $\downarrow 0.4903 \pm 0.18$ & $0.52 \pm 0.10$ & 0.4154, NS \\
\hline $\mathrm{HF}(\mathrm{nu})$ & $\downarrow 0.4417 \pm 0.1994$ & $0.48 \pm 0.1$ & 0.3673, NS \\
\hline LF:HF & $\downarrow 0.9480 \pm 0.7754$ & $1.194 \pm 0.526$ & $0.1551, N S$ \\
\hline \multicolumn{4}{|c|}{ Time domain parameters } \\
\hline SDNN (ms) & $43.899 \pm 13.65$ & $42.92 \pm 10.36$ & $0.7632, \mathrm{NS}$ \\
\hline RMSSD (ms) & $36.43 \pm 16.27$ & $35.17 \pm 11.34$ & $0.7289, \mathrm{NS}$ \\
\hline SDSD (ms) & $35.35 \pm 16.91$ & $34.37 \pm 11.59$ & $0.7935, \mathrm{NS}$ \\
\hline NN50 Count & $48.50 \pm 52.0$ & $50.57 \pm 33.22$ & $0.8551, \mathrm{NS}$ \\
\hline pNN50\% & $14.38 \pm 14.87$ & $12.83 \pm 9.29$ & 0.6294, NS \\
\hline SD1/SD2 & $\uparrow 0.51 \pm 0.15$ & $0.46 \pm 0.1$ & 0.1648, NS \\
\hline \multicolumn{4}{|c|}{ 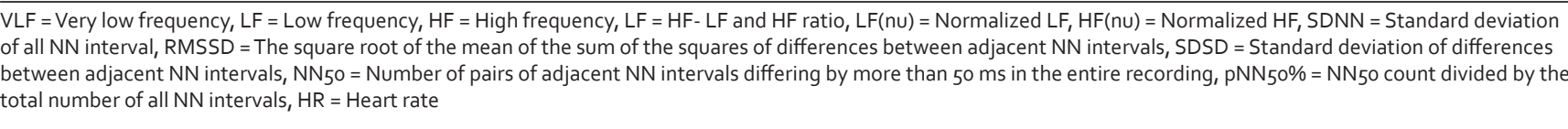 } \\
\hline \multicolumn{4}{|c|}{$\begin{array}{l}\text { Table 3: Comparative values of frequency domain parameters and time domain parameters between } 3^{\text {rd }} \\
\text { trimester pregnant subjects and healthy non pregnant controls }\end{array}$} \\
\hline Parameters & $\begin{array}{c}3^{\text {rd }} \text { trimester of gestation Mean } \pm \text { SD Cor } \\
(n=30)\end{array}$ & $\begin{array}{l}\text { non pregnant Mean } \pm \text { SD } \\
\quad(n=30)\end{array}$ & $P$-value \\
\hline \multicolumn{4}{|c|}{ Frequency domain parameters } \\
\hline $\operatorname{VLF}\left(\mathrm{ms}^{2}\right)$ & $\downarrow 858.82 \pm 773.55$ & $1059.9 \pm 503.57$ & 0.2376, NS \\
\hline $\operatorname{LF}\left(\mathrm{ms}^{2}\right)$ & $\downarrow 425.09 \pm 361.72$ & $979.49 \pm 696.1$ & $0.0003, \mathrm{~S}$ \\
\hline $\mathrm{HF}\left(\mathrm{ms}^{2}\right)$ & $\downarrow 201.03 \pm 179.79$ & $906.72 \pm 674.94$ & $<0.0001, \mathrm{~S}$ \\
\hline LF (nu) & $\uparrow 0.7273 \pm 0.12$ & $0.52 \pm 0.10$ & $<0.0001, \mathrm{~S}$ \\
\hline HF (nu) & $\downarrow 0.2663 \pm 0.1030$ & $0.48 \pm 0.1$ & $<0.0001, \mathrm{~S}$ \\
\hline LF: HF & $\uparrow 2.930 \pm 1.785$ & $1.194 \pm 0.526$ & $0.0001, \mathrm{~S}$ \\
\hline \multicolumn{4}{|c|}{ Time domain parameters } \\
\hline SDNN (ms) & $\downarrow 27.93 \pm 12.5$ & $42.92 \pm 10.36$ & $0.0001, \mathrm{~S}$ \\
\hline RMSSD (ms) & $\downarrow 22.25 \pm 19.29$ & $35.17 \pm 11.34$ & $0.0025, \mathrm{~S}$ \\
\hline SDSD (ms) & $\downarrow 21.35 \pm 18.68$ & $34.37 \pm 11.59$ & $0.0020, \mathrm{~S}$ \\
\hline NN50 Count & $\downarrow 20.67 \pm 56.62$ & $50.57 \pm 33.22$ & $0.0155, \mathrm{~S}$ \\
\hline pNN50 \% & $\downarrow 5.96 \pm 15.15$ & $12.83 \pm 9.29$ & $0.0387, \mathrm{~S}$ \\
\hline SD1/SD2 & $\uparrow 0.47 \pm 0.3$ & $0.46 \pm 0.1$ & $0.9452, \mathrm{NS}$ \\
\hline
\end{tabular}




\begin{tabular}{|c|c|c|c|}
\hline Parameters & $1^{\text {st }}$ trimester of gestation (Mean \pm SD) $(n=30)$ & $3^{\text {rd }}$ trimester of $($ Mean \pm SD) $(n=30)$ & $P$-value \\
\hline \multicolumn{4}{|c|}{ Frequency domain parameters } \\
\hline $\operatorname{VLF}\left(\mathrm{ms}^{2}\right)$ & $1107.7 \pm 720.42$ & $\downarrow 858.82 \pm 773.55$ & 0.1115, NS \\
\hline $\mathrm{LF}\left(\mathrm{ms}^{2}\right)$ & $899.19 \pm 527.80$ & $\downarrow 425.09 \pm 361.72$ & 0.0001, ES \\
\hline $\mathrm{HF}\left(\mathrm{ms}^{2}\right)$ & $801.06 \pm 898.32$ & $\downarrow 201.03 \pm 179.79$ & $0.0007, \mathrm{ES}$ \\
\hline LF (nu) & $0.4903 \pm 0.18$ & $\uparrow 0.7273 \pm 0.12$ & $<0.0001$, ES \\
\hline $\mathrm{HF}(\mathrm{nu})$ & $0.4417 \pm 0.1994$ & $\downarrow 0.2663 \pm 0.1030$ & $<0.0001$, ES \\
\hline LF: HF & $0.9480 \pm 0.7754$ & $\uparrow 2.930 \pm 1.785$ & $<0.0001$, ES \\
\hline \multicolumn{4}{|c|}{ Time domain parameters } \\
\hline SDNN (ms) & $43.899 \pm 13.65$ & $\downarrow 27.93 \pm 12.5$ & $<0.0001$, ES \\
\hline RMSSD (ms) & $36.43 \pm 16.27$ & $\downarrow 22.25 \pm 19.29$ & $0.0032, \mathrm{~S}$ \\
\hline $\operatorname{SDSD}(\mathrm{ms})$ & $35.35 \pm 16.91$ & $\downarrow 21.35 \pm 18.68$ & $0.0035, \mathrm{~S}$ \\
\hline NN50 Count & $48.50 \pm 52.0$ & $\downarrow 20.67 \pm 56.62$ & $0.0521, N S$ \\
\hline pNN50\% & $14.38 \pm 14.87$ & $\downarrow 5.96 \pm 15.15$ & $0.0339, \mathrm{~S}$ \\
\hline SD1/SD2 & $0.51 \pm 0.15$ & $\downarrow 0.47 \pm 0.3$ & $0.4940, N S$ \\
\hline Tri. HRV Index & $11.4 \pm 3.95$ & $\downarrow 7.72 \pm 2.96$ & $0.0001, \mathrm{~S}$ \\
\hline \multicolumn{4}{|l|}{ Others } \\
\hline Mode Value & $602.23 \pm 125.29$ & $\uparrow 643.06 \pm 85.62$ & $0.1459, \mathrm{NS}$ \\
\hline $\mathrm{HR}$ & $80.4 \pm 2.94$ & $\uparrow 85.2 \pm 3.5$ & $<0.0001$, ES \\
\hline Avg R-R & $738.31 \pm 95.32$ & $\downarrow 689.67 \pm 97.98$ & $0.0561, \mathrm{NS}$ \\
\hline
\end{tabular}

and healthy non-pregnant control subjects. However, LF, HF and normalized HF were reduced in $1^{\text {st }}$ trimester of gestation subjects. This may be due to the effect of maternal or placental hormones during the early phase of pregnancy.

Stein et al., reported that in early pregnancy, statistical differences in the spectral indexes tend to be smaller than in late pregnancy with major contradictions in the published data. ${ }^{[13]}$ They were no reported significant differences in early pregnancy (with respect to non-pregnancy) except for $\mathrm{LF}$ region and RRsd and mainly, during the sleep-time but no differences were observed at all with respect to late pregnancy. ${ }^{[13]}$ This study among $1^{\text {st }}$ trimester of gestation shows similar type of result.

As per Table 3, there were statistical significant difference in the mean values of frequency domain parameters and time domain parameters among the $3^{\text {rd }}$ trimester of gestation in pregnancy subjects and healthy non- pregnant control subjects. Frequency domain parameters like VLF $\left(858.82 \pm 773.55 \mathrm{~ms}^{2}\right)$, LF (425.09 $\left.\pm 361.72 \mathrm{~ms}^{2}\right)$, HF $\left(201.03 \pm 179.79 \mathrm{~ms}^{2}\right)$ and normalized $\operatorname{HF}(0.2663 \pm 0.1030)$ were significantly reduced and normalized LF $(0.7273 \pm 0.12)$, LF: HF $(2.930 \pm 1.785)$ was significantly incremented in the $3^{\text {rd }}$ trimester of gestation as compared to non-pregnant healthy control and of $1^{\text {st }}$ trimester of gestation [Table 4]. These represent the sympathetic modulation or over activity become prominent and vagal or parasympathetic inhibition or blockage occurs during the $3^{\text {rd }}$ trimester of gestation in normal pregnancy. During the $3^{\text {rd }}$ trimester of gestation, time domain parameters, $\operatorname{SDNN}(27.93 \pm 12.5 \mathrm{~ms})$, RMSSD $(22.25 \pm 19.29 \mathrm{~ms}), \operatorname{SDSD}(21.35 \pm 18.68 \mathrm{~ms})$, NN50 $(20.67 \pm 56.62)$ count, pNN50 (5.96 \pm 15.15) were significantly reduced and SD1/SD2 $(0.47 \pm 0.3)$ was increased as compare with Control group. This may be interpreted as sympathetic modulation due to vagal inhibition during that stage.
Greenwood et al. ${ }^{[14]}$ found that the vasomotor sympathetic activity increased in women with normal pregnancy and was even greater in hypertensive pregnant women during the $3^{\text {rd }}$ trimester of gestation. They concluded that the marked sympathetic hyperactivity during the latter months of normal pregnancy helped to return the arterial pressure to non-pregnant levels, but when the increase in sympathetic nerve activity was excessive, hypertension ensued. Their preliminary data suggest that normal pregnancy may also be associated with an increase in resting vasomotor sympathetic outflow, and pregnancy per se can result in sympathetic activation despite a normal blood pressure. That is quite comparable to our study result as LF: HF and LF (nu) increment during the $3^{\text {rd }}$ trimester of gestation that represents the sympathetic over activity.

As per Table 4, in frequency domain parameters, mean values of VLF, LF, HF, HF normalized were significantly reduced in $3^{\text {rd }}$ trimester of gestation in pregnancy and mean values of LF: HF and LF normalized were significantly increased during the $3^{\text {rd }}$ trimester of pregnancy as compared to the $1^{\text {st }}$ trimester of gestation in pregnancy. This shows the sympathetic dominance is more during $3^{\text {rd }}$ trimester of pregnancy as compared to $1^{\text {st }}$ trimester of gestation. Reduction in $\mathrm{HF}$ and LF during $3^{\text {rd }}$ trimester of gestation in pregnancy shows the decreased activity of parasympathetic system or its turn to developing vagal blockage as pregnancy advance.

In normalized units, an increased LF $(0.7273 \pm 0.12)$ and a diminished $\operatorname{HF}(0.2663 \pm 0.1030)$ were observed during $3^{\text {rd }}$ trimester of gestation in pregnancy. These indicate a shift of sympathovagal balance towards a sympathetic predominance and a reduced vagal tone during $3^{\text {rd }}$ trimester of gestation. Similar conclusions were obtained by considering the changes in LF/HF ratio. Significant reduction in RMSSD, NN50 count, $\mathrm{pNN} 50 \%$ and $\mathrm{HF}\left(\mathrm{ms}^{2}\right)$ during 
the $3^{\text {rd }}$ trimester of pregnancy suggest marked reduction in vagal modulation in HRV regulation and aggravate in sympathovagal imbalance.

SDNN is mathematically equal to total power of spectral analysis; SDNN reflects all the cyclic components responsible for variability in the period of recording. The mean values of SDNN were reduced in $3^{\text {rd }}$ trimester $(27.93 \pm 12.5)$ of pregnancy as compared to $1^{\text {st }}$ trimester $(43.899 \pm 13.65)$ of pregnancy. Reduction in SDNN represents abnormally low HRV with sympathovagal imbalance is more during $3^{\text {rd }}$ trimester even in normal pregnancy.

Heiskanen et als., ${ }^{[15]}$ study showed that in normal pregnancy, the increment of the heart rate could be partially associated with the inhibition of resting parasympathetic activity connected with an increment of the sympathetic modulation but during the $3^{\text {rd }}$ third trimester of pregnancy there could be a parasympathetic deactivation instead of an increment of the sympathetic activity (under unstimulated conditions) even when the head-up tilt test induce changes in the parasympathetic activity and the sympathovagal balance.

The presence of a high vagal tone seems to be a marker of physiological, biological and psychological flexibility. So, decreased vagal tone in $3^{\text {rd }}$ trimester of gestation group in our study may cause loss of flexibility in physiological systems in general, and in the cardiovascular system in particular, which has been linked with a number of diseases and dysfunctions. So, abnormally low heart rate variability in our study indicates that even normal pregnancy without any complication can impact dramatically on dynamic autonomic control of heart. This is an issue that requires inter-disciplinary approaches across multiple levels of analysis, ranging from the psychological to the biochemical investigation.

\section{CONCLUSION}

As normal pregnancy advances in its stage, the inhibition of resting parasympathetic activity connected with an increment of the sympathetic modulation is noted. The effect of sympathetic dominance may be controlled by other mechanism of the body during the $3^{\text {rd }}$ trimester of gestation in pregnancy such as regulation of blood pressure, heart rate and cardiac output in normal pregnancy. HRV can be applied as early diagnosis of pregnancy induced cardiac abnormalities with correlate it with other investigation.

\section{REFERENCES}

1. Clifford GD, Azuaje F, McSharry PE. Advanced methods and tools for ECG data analysis. AARTECH House Publishing April 2006.

2. Task Force of the European Society of Cardiology and the North American Society of Pacing and Electrophysiology. Standards of measurement, physiological interpretation, and clinical use. Circulation 1996;93:1043-65.

3. Pivarnik JM, Lee W, Clark SL, Cotton DB, Spillman HT, Miller JF. Cardiac output responses of primi-gravid women during exercise determined by the direct Fick technique. Obstet Gynecol 1990;75:954-9.

4. Sady SP, Carpenter MW, Thompson PD, Sady MA, Haydon B, Coustan DR. Cardiovascular response to cycle exercise during and after pregnancy. J Appl Physiol (1985) 1989;66:336-41.

5. Duvekot JJ, Cheriex EC, Pieters FA, Menheere PP, Peters LL. Early pregnancy changes in hemodynamics and volume homeostasis are consecutive adjustments triggered by a primary fall in systemic vascular tone. Am J Obstet Gynecol 1993;169:1382-92.

6. Akselrod S, Gordon D, Madwed JB, Snidman NC, Shannon DC, Cohen RJ. Hemodynamic regulation: Investigation by spectral analysis. Am J Physiol 1985;249:H867-75.

7. Akselrod S, Gordon D, Ubel FA, Shannon DC, Berger AC, Cohen RJ. Power spectral analysis of heart rate fluctuation: A quantitative probe of beat to beat cardiovascular control. Science 1981;213:220-2.

8. Berger RD, Saul JP, Cohen RJ. Transfer function analysis of autonomic regulation. I. Canine atrial rate response. Am J Physiol Heart Circ Physiol 1989;256:H142-52.

9. Novak V, Novak P, de Champlain J, Le Blanc AR, Martin R, Nadeau R. Influence of respiration on heart rate and blood pressure fluctuations. J Appl Physiol 1993;74:617-26.

10. Ekholm EM, Erkkola RU, Piha SJ, Jalonen JO, Metsala TH, Antila KJ. Changes in autonomic cardiovascular control in mid-pregnancy. Clin Physiol 1992;12:527-36.

11. Ekholm EM, Piha SJ, Antila KJ, Erkkola RU. Cardiovascular autonomic reflexes in mid-pregnancy. Br J Obstet Gynaecol 1993;100:177-82.

12. Ekholm EM, Hartiala J, Huikuri HV. Circadian rhythm of frequency-domain measures of heart rate variability in pregnancy. $\mathrm{Br} \mathrm{J}$ Obstet Gynaecol 1997; 104:825-8.

13. Stein PK, Hagley MT, Cole PL, Domitrovich PP, Kleiger RE, Rittman JN. Changes in 24-hour heart rate variability during normal pregnancy. Am J Obstet Gynecol 1999;180:978-85.

14. Greenwood JP, Scott EM, Stoker JB, Walker JJ, Mary DA. Sympathetic neural mechanisms in normal and hypertensive pregnancy in humans. Circulation 2001;104:2200-4.

15. Heiskanen N, Saarelainen $H$, Valtonen P, Lyyra-Laitinen T, Laitinen $T$, Vanninen $\mathrm{E}$, et al. Blood pressure and heart rate variability analysis of orthostatic challenge in normal human pregnancies. Clin Physiol Funct Imaging 2008;28:384-90.

How to cite this article: Gandhi PH, Mehta HB, Gokhale AV, Desai CB, Gokhale PA, Shah CJ. A study on cardiac autonomic modulation during pregnancy by non-invasive heart rate variability measurement. Int J Med Public Health 2014;4:441-5.

Source of Support: Nil, Conflict of Interest: None declared. 